\title{
PROGNOSTIC FACTORS FOR LYMPH AND DISTANT METASTASES IN PATIENTS WITH MALIGNANT MELANOMA - A 4-YEAR ANALYSIS OF CLINICAL RESULTS
}

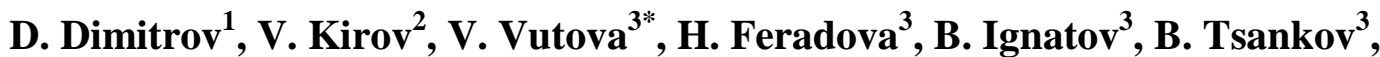 \\ S. Hristova ${ }^{3}$, G. Valcheva ${ }^{1}$, V. Nanev ${ }^{1}$, M. Nikolova ${ }^{4}$, T. Deliyski ${ }^{1}$ \\ ${ }^{1}$ Department of Surgical Oncology, Medical University of Pleven, Bulgaria \\ ${ }^{2}$ Consultative-Diagnostic Oncology Center, Medical University of Pleven, Bulgaria \\ ${ }^{3}$ Student Study-research Group of Surgical Oncology, Medical University of Pleven, Bulgaria \\ ${ }^{4}$ Department of General and Clinical Pathology, Medical University of Pleven, Bulgaria
}

\begin{abstract}
PURPOSE: Our aim was to define some prognostic factors for lymph and distant metastases in cases of malignant melanoma (MM), treated in the Oncology Center at the University Hospital "Dr George Stranski" - Pleven in a 4-year period.

METHODS: A research index card was used to process the oncologic files of 82 out of 102 patients with MM, treated and monitored in the Oncology center between 01.01.2008 and 31.12.2011. TNMstages, Breslow and Clark levels, location, characteristics of the skin lesion, size, diagnostic excision, lymph node dissection type, etc. were registered in the index card.

RESULTS: The most common location of the skin lesion was on the back-23cases (28.5\%). The prevalent type was the nodular form-28 cases (28.05\%). In 37cases (45.1\%) Breslow thickness was 1 to $3 \mathrm{~mm}$, Clark levels-3 or 4 . Out of all the patients $43(52.4 \%)$ were locally advanced T3 and T4 stage cases. In 9 cases $(10.9 \%)$ distant metastases were found during the diagnosis of the disease. There are 13 cases of MM patients with lymph metastases.

CONCLUSOINS: The nodular and achromatic type MM showed more often lymph node metastases $(p=0.029)$. The Clark level was in close relation with lymph node metastases $(p=0.07)$. The time of distant metastases turned out to be in a close relation with the size of the primary lesion $(\mathrm{p}=0.029)$.
\end{abstract}

Key words: malignant melanoma, lymph and distant metastases, prognostic factors

\section{INTRODUCTION}

Over the last 30 years the number of malignant melanoma (MM) cases in Bulgaria has increased three times $(0.5 / 100.000-1980$ and 1.6/ 100.000 - 2010), still it remains a rare disease (1). The global tendency shows a growth in the number of reported cases and reveals its social importance due to high mortality rates of patients (2- 5). In the last 20 years, the algorithm for melanoma diagnosis, staging and treatment has significantly changed. In the literature the prognostic factors for lymph and distant metastases are still under discussion (3). Some authors suggest that the Clark's level is not a histological prognostic factor for MM aggression (4).

\footnotetext{
*Correspondence to: Vasya Vutova, Department of Surgical Oncology, University Hospital "Dr George Stranski” - Pleven, Bulgaria, 8A “George Kotchev' Str, 5800 Pleven, Bulgaria, Tel.: +359 64886 242, E-mail: vasya90@abv.bg
}

The clinical types of $\mathrm{MM}$ are as it follows: Lentigo maligna, Lentigo maligna melanoma, Superficial spreading melanoma, Acral lentiginous melanoma, Mucosal melanoma, Nodular melanoma, Polypoid melanoma, Desmoplastic melanoma, Amelanotic melanoma, Soft-tissue melanoma (6). The neoplastic cells in MM are generally markedly atypical and pleomorphic, with large hyperchromatic nuclei and a prominent nucleolus. Mitotic activity is increased. There are two types of tumor cells that MM consists: spindle-shaped cells and epithelioid cells (7). The histological appearance of MM we present in Figure 1.

The T category of the TNM staging of MM lesions is defined by Clark level and Breslow thickness. Clark level describes five levels of anatomical invasion of the melanoma in the skin from the epidermis through the papillary and reticular dermis to subcutaneous fat. 
Breslow thickness, determined directly by ocular micrometer (and measured in SI millimeters) shows the depth of invasion of tumor cells down from the granular layer of the epidermis. Melanomas less than $0.76 \mathrm{~mm}$ are classified as very thin, melanomas from 0.76 to $1.5 \mathrm{~mm}$ are thin, melanomas $1.5-3.0 \mathrm{~mm}$ are
DIMITROV D., et al. intermediate, and thick melanomas are over 3.0 $\mathrm{mm}$ (6). The most important prognostic factor in $\mathrm{MM}$ is Breslow thickness and ulceration status (2). The measurement of the Breslow thickness is most accurately done by diagnostic excision (7).

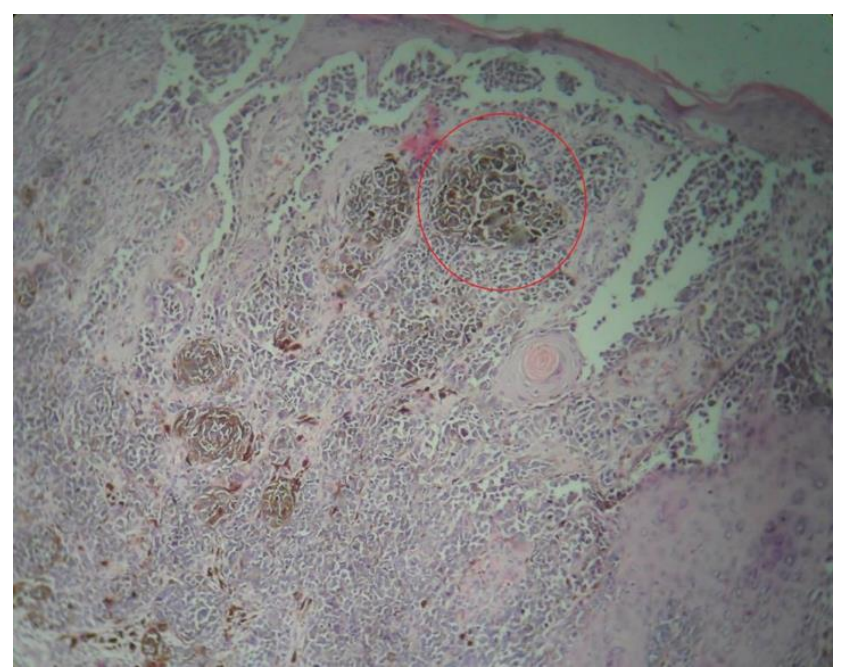

Figure 1. Histological appearance of MM (Melanin is usually present in the abundant cytoplasm)

\section{AIM}

Our aim is to define some prognostic factors for lymph and distant metastases in cases of $\mathrm{MM}$, treated in the Oncology Center at the University Hospital "Dr George Stranski" Pleven in a 4-year period.

\section{MATERIALS AND METHODS}

A research index card was used to process the oncologic files of 82 out of 102 patients with $\mathrm{MM}$, treated and monitored at the Oncology Center at the University Hospital "Dr George Stranski" - Pleven, Bulgaria between 01.01.2008 and 31.12.2011. Medical documentation was missing from the files of 20 patients. The data was processed and analysed by the student study-research group of Surgical Oncology from Medical University-Pleven for 2 months. Age, sex, TNM-stages, Breslow and Clark levels, location, characteristics of the skin lesion, size, diagnostic excision, lymph node dissection type, number of sentinel lymph nodes (SLN), localization of SLN, postoperative chemotherapy, imaging data etc. were registered in the index card.

In our study the most common location of the skin lesion was on the back - 23 cases (28\%). The prevalent type of lesion was the nodular form - 28 cases $(28.05 \%)$. Distribution according to the location of the lesion in our research is demonstrated in Figure 2. The predominant site was the back, followed by the upper and lower limbs. The distribution of the melanomas according to their type is shown in Figure 3. We also gathered data about the size of the malignant lesion (Figure 4), with most of them being below $3 \mathrm{~cm}$. All the cases were histologically proven and Breslow and Clark level were measured by the pathologists.

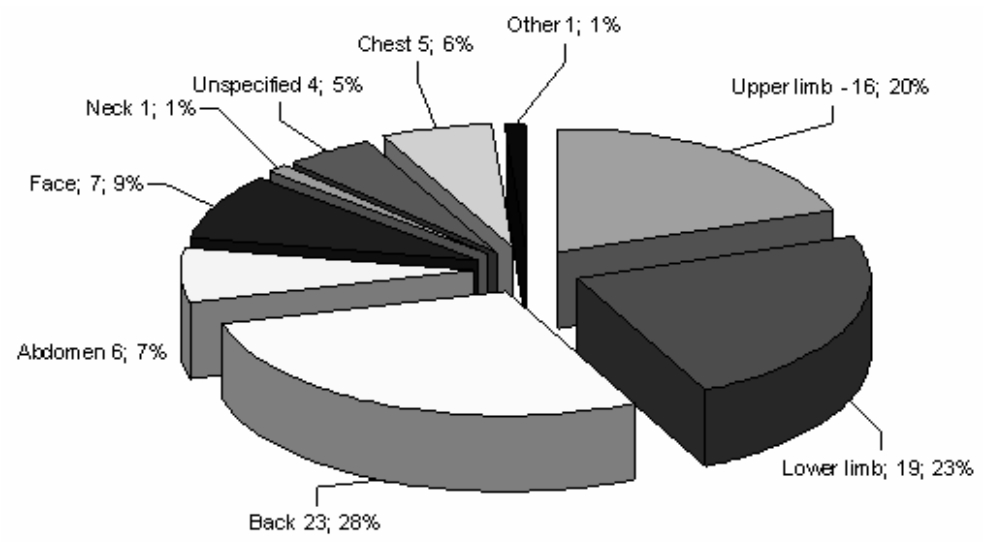

Figure 2. Distribution according to lesion location 


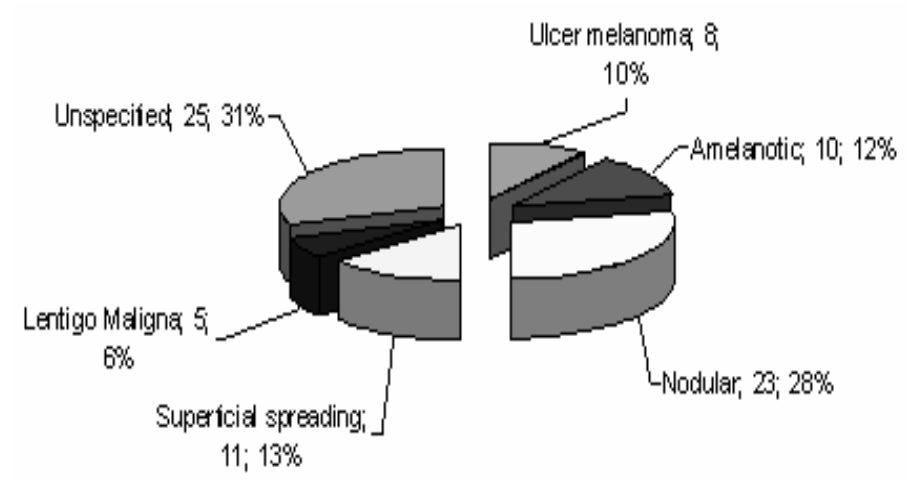

Figure 3. Distribution according to the type of melanoma

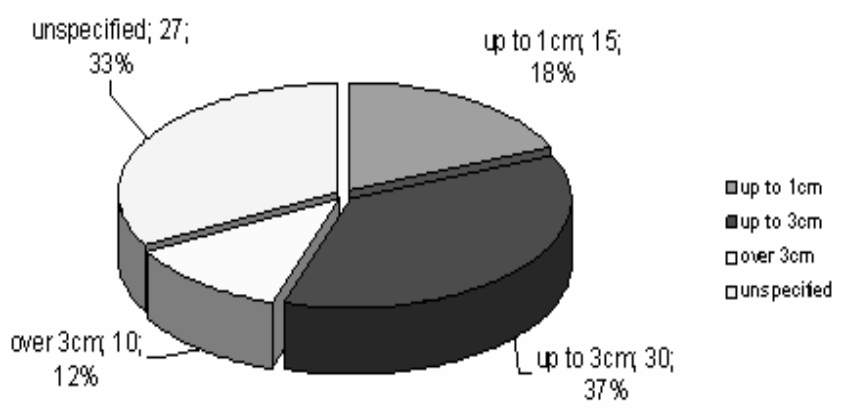

Figure 4. Distribution according to lesion size

The algorithm of diagnosis and treatment (Figure 5) in our Department of Surgical Oncology was based on the interdisciplinary approach to melanoma. In the process of diagnosis and treatment dermatologists, surgical oncologist, medical oncologist and nuclear medicine physicians took part.
The analysis of the data was made with the Statgraphics plus program. The statistical methods used were alternative analysis, analysis of variance, graphical analysis and correlation analysis.

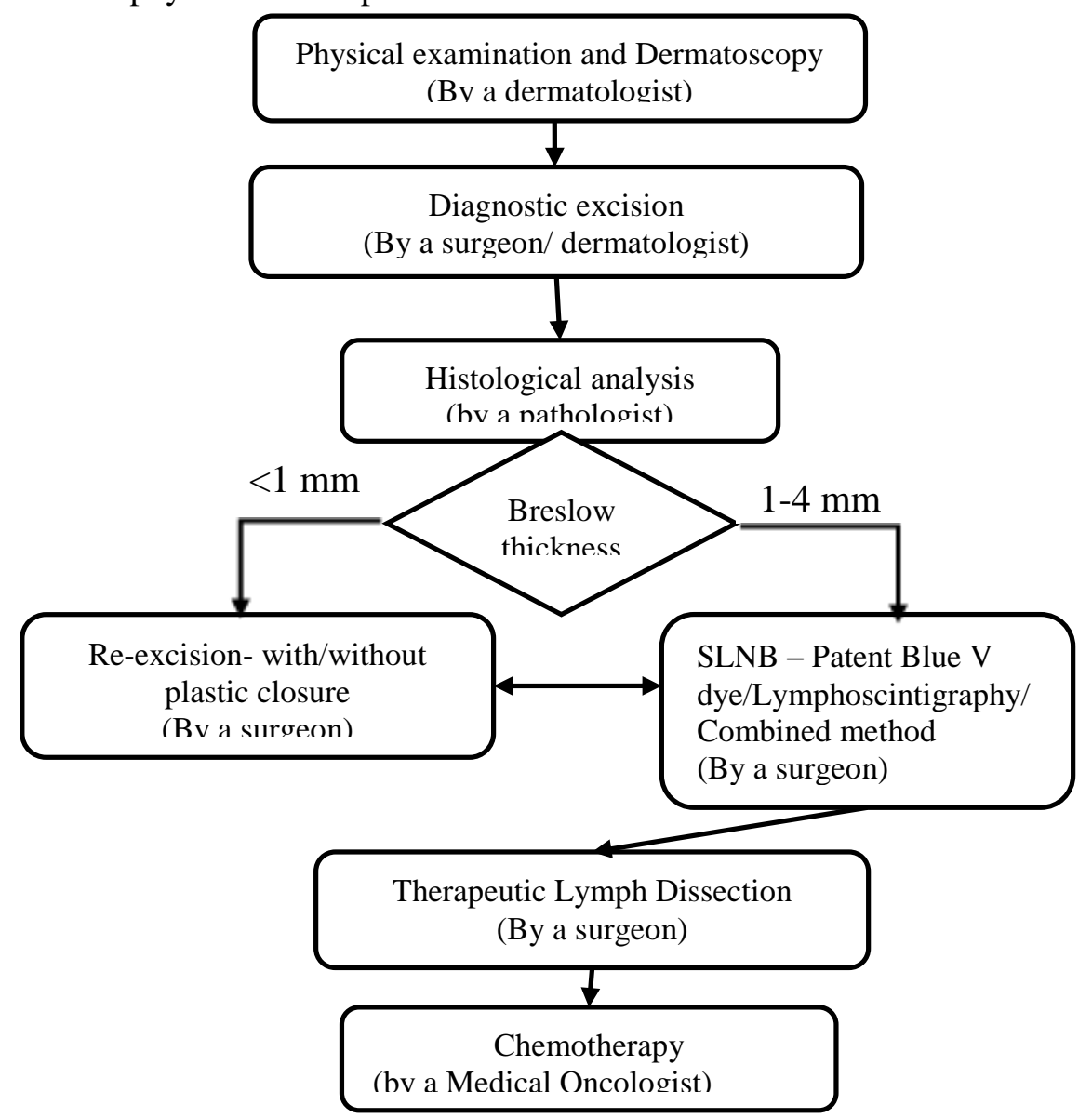

Figure 5. Interdisciplinary approach to Malignant Melanoma treatment and management 


\section{RESULTS}

In 37 of our cases (45.1\%) Breslow thickness was 1 to $3 \mathrm{~mm}$. In the same patients Clark levels were up to 3 to 4 . Out of all the patients, $43(52.4 \%)$ were locally advanced T3 and T4 stage cases. The next two figures show the distribution of the patient number according to Breslow thickness and Clark level (Figure 6 and Figure 7).

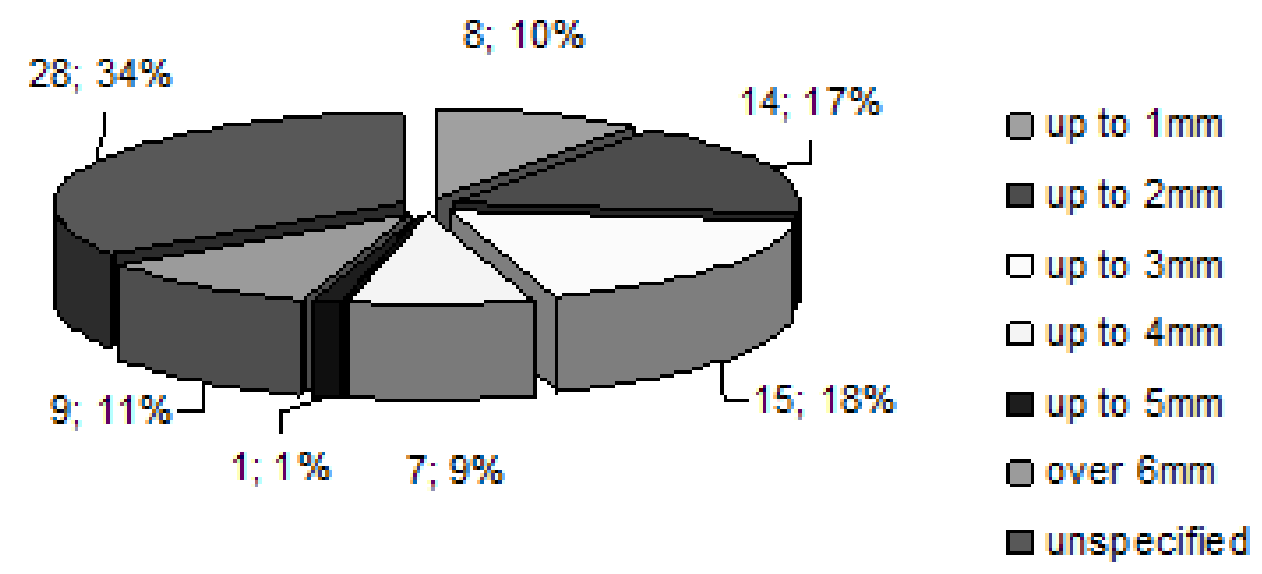

Figure 6. Distribution according to Breslow thickness

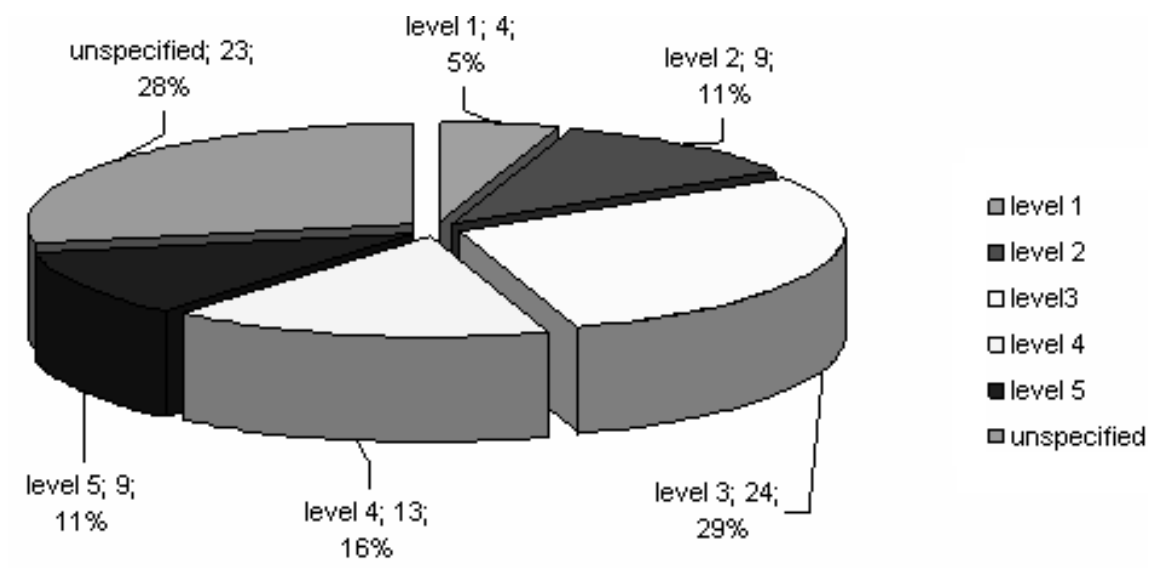

Figure 7. Distribution according to Clark level

In our study 9 cases (10.9\%) with distant metastases during the diagnosis of the disease and 13 cases $(15.9 \%)$ with lymph metastases were found. No distant metastases were detected in $72 \%$ from all the cases. The distribution of the distant metastases is shown on a Table 1.

Table 1. Distribution of the distant metastases of the patients.

\begin{tabular}{|l|l|l|}
\hline Location & Cases & $\%$ \\
\hline Multiple organs & 10 & $13 \%$ \\
Suprarenal glands & 5 & $6 \%$ \\
Lungs & 4 & $5 \%$ \\
Brain & 2 & $3 \%$ \\
Liver & 1 & $1 \%$ \\
None & 57 & $72 \%$ \\
\hline
\end{tabular}

The last occurred in different period of time during the diagnosis and treatment of the patients - Table 2. 
Table 2. Distribution according time of distant metastases of the patients.

\begin{tabular}{|l|l|l|}
\hline $\begin{array}{l}\text { Time of metastases after } \\
\text { diagnosis }\end{array}$ & Cases & $\%$ \\
\hline Up to 6 months & 7 & $32 \%$ \\
\hline Over 6 months & 3 & $14 \%$ \\
\hline Over 1 year & 7 & $32 \%$ \\
\hline Over 2 years & 1 & $4 \%$ \\
\hline At the time of diagnosis & 4 & $18 \%$ \\
\hline
\end{tabular}

Two patients out of $10(20 \%)$ with lesions larger than $3 \mathrm{~cm}$ had metastases up to 6 months after diagnosis. In 8cases (26.6\%) out of 30 patients with lesions $1-3 \mathrm{~cm}$ distant metastases appeared longer than 6 months after diagnosis. In our research the time of metastases turned out to be in a close relation with the size of the primary lesion $(\mathrm{p}=0.029)$.

In our study the Clark level was in close relation with lymph node metastases $(\mathrm{p}=0.07)$ - most patients were with Clark 3 level melanoma. Therapeutic lymph node dissection and lesion size were also related $(\mathrm{p}=0.037)$. It was carried out in: none of the lesions with diameter up to $1 \mathrm{~cm}$; in $30 \%$ of patients (9 out of 30 cases) with lesion diameter 1 to $3 \mathrm{~cm}$; $10 \%$ of patients (1out of 10 cases) with lesion diameter more than $3 \mathrm{~cm}$. In our retrospective cohort the nodular and achromatic types of melanoma showed more often lymph node metastases $(p=0.029)$ than the other types while the superficial spreading melanoma and lentigo maligna cases showed N0.

\section{CONCLUSIONS}

Using the retrospective correlative and variable analysis, our research group tried to define some prognostic factors for lymph and distant metastases in patients with MM according our 4 years clinical experience. In our research, the number of patients with locally advanced $\mathrm{MM}$ is higher than the one in the literature. This rises the necessity to perform more lymph node dissections during the staging and treatment of patients with MM which in turn worsens the clinical results.

In different studies other authors suggest that primary thickness (Breslow and Clark), primary site, tumor size and number of tumorpositive SLN are significantly associated with lymph node metastases $(8,9)$. In multivariate analysis Parett et al. (2011) showed that the maximum metastatic size and primary melanoma thickness were the most important prognostic factors for progression-free survival and overall survival [10]. Results of our research are corresponding with this data.

In our study the nodular and achromatic types of melanoma showed more often lymph node metastases $(\mathrm{p}=0.029)$. In a clinical study which involves 17600 melanoma patients, Balch et all (2001) found similar results (2).

The analysis covered the main criteria in the diagnosis and treatment of Malignant Melanoma. According to our research as a prognostic factors for lymph node metastases in $\mathrm{MM}$ patients we can defined: lesion size $(\mathrm{p}=0.037)$, nodular or achromatic types of melanoma $(\mathrm{p}=0.029)$ and Clark level $(\mathrm{p}=0.07)$. The time of distant metastases is in close relation with the size of the primary lesion $(\mathrm{p}=0.029)$.

\section{REFERECES}

1. Dimitrova N, Vukov M, Valerianova Z., Cancer incidence in Bulgaria 2009. Bulgarian National Cancer Registry, Volume XX: 12-28, 2011

2. Balch CM. et al., Prognostic Factors Analysis of 17,600 Melanoma Patients: Validation of the American Joint Committee on Cancer Melanoma Staging System. J Clin Oncol, 15; 19(16):3622-34, 2001

3. Balch CM, Murad TM, Soong SJ, et al., A multifactorial analysis of melanoma: Prognostic histopathologic features comparing Clark's and Breslow's staging methods. Ann Surg, 188: 732-742, 1978

4. Eldh J, Boeryd B, Peterson LE., Prognostic factors in cutaneous malignant melanoma in stage I: A clinical, morhological and multivariate analysis. Scand $J$ Plast Reconstr Surg Hand Surg, 12: 243255, 1978 
5. Van Der Esch EP, Cascinelli N, Preda F, et al., Stage I melanoma of the skin: Evaluation of prognosis according to histologic characteristics. Cancer, 48: 16681673,1981

6. William J., Berger T., Elston D., Andrews' Diseases of the Skin: clinical Dermatology. Saunders Elsevier, pp. 694-9, 2006

7. Sanchez RL., Raimer SS., Vademecum Dermatopathology. Landes Bioscience, Texas, USA, pp. 287-291, 2001

8. Marghoob AA, Koenig K, Bittencourt FV, Kopf AW, Bart RS., Breslow thickness and Clark level in melanoma: support for including level in pathology reports and American Joint Committee on Cancer Staging. Cancer, 88(3):589-95,2000
DIMITROV D., et al.

9. Lee JH., Essner R., Torisu-Itakura H., Wanek L., Wang H., Morton DL., Factors Predictive of Tumor-Positive Nonsentinel Lymph Nodes After Tumor-Positive Sentinel Lymph Node Dissection for Melanoma. J Clin Oncol, 15;22(18):367784, 2004

10.Parrett B., Fadaki L., Rhee J., Leong S., The Biology and Clinical Relevance of Sentinel Lymph Nodes in Melanoma. In: Murph M., Melanoma in the Clinic Diagnosis, Management and Complications of Malignancy. Intech, pp. 225-239, 2011 